\section{Viviendas progresivas}

\section{Gómez Agusti ${ }^{\star}$}

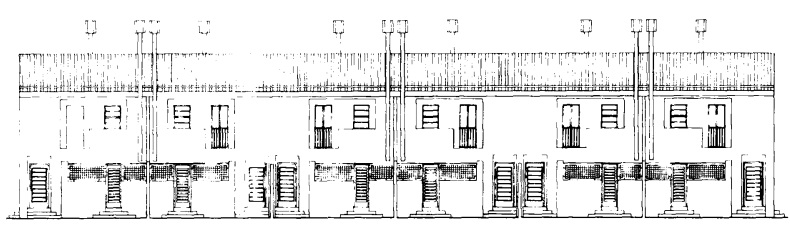

Alzado anterior

\section{INTRODUCCIÓN}

El proyecto de viviendas de bajo coste de adquisición se engloba en los temas de experimentación que, en su día, llevó a cabo la Dirección General de Arquitectura de la Comunidad Autónoma de Madrid. Aunque entrelazado con los otros proyectos a la hora de definición física del tema es el fruto, en parte, de otra serie de investigaciones realizadas en el I.P.P.V. bajo la dirección de Luis Miquel, entonces Subdirector General.

\section{ANTECEDENTES EN EL I.P.P.V.}

En los temas indicados anteriormente teníamos como objetivos la reducción de costes y racionalización de la construcción y la participación del usuario. Rescatamos del olvido un tema interesante propuesto en el antiguo I.N.V., que era el de "viviendas perfectibles", en el que el usuario tendría que hacer frente, por sus medios, a ciertos acabados que encarecian la vivienda, tales como pavimentos, rodapiés, ciertas puertas, alicatados, que se sustituian provisionalmente por pintura impermeable, etc. Este tema establecía de un modo muy somero una jerarquización, que precisamente ha sido uno de los invariantes en los que durante años me han ayudado personalmente en la clarificación del concepto general de la vivienda. Precisamente presenté, posteriormente, una comunicación al Certamen Internacional de Vivienda Social (C.I.N.T.U.S.) en 1987 basado en lo Perfectible de la vivienda mediante la aportación del usuario. En esta comunicación se establecía que con ahorros del 20 por 100 en el costo de la vivienda se llegaba a poder realizar un 25 por 100 más de viviendas. Hubo un tema, en 1984, aprobado por el en-

* Moreto, $5,1 .{ }^{\circ}$

28014 Madrid/España

(C) Consejo Superior de Investigaciones Científicas

Licencia Creative Commons 3.0 España (by-nc)

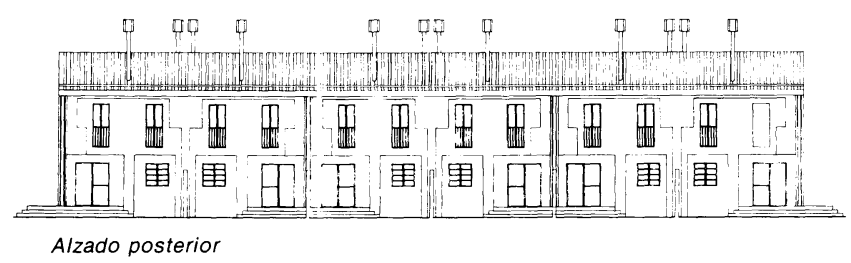

tonces Director General del I.P.P.V., Francisco Vera, para llevar a cabo una experiencia de SISTEMA ABIERTO, que podía haber sido el embrión de un tema de racionalización de costes. Sin embargo, un cambio en la Dirección General, ocupada por José Luis González Haba, que personalmente no creía en el tema, truncó una experiencia que nos hubiera acercado a progresar en los temas de vivienda. Es de lamentar que los políticos, en temas de investigación, no se informen bien personalmente o bien mediante colaboradores, y se atengan exclusivamente a su intuición personal. Porque realmente todas las investigaciones realizadas en Europa y que hacen la construcción más racional, con costes más controlados, sistemas constructivos mejores y de mayor calidad, merecen un esfuerzo y no la célebre frase "que inventen ellos".

\section{INVESTIGACIÓN EN LA DIRECCIÓN GENERAL DE ARQUITECTURA}

Afortunadamente Luis Miquel, al ser nombrado Director General de Arquitectura de la Comunidad Autónoma de Madrid, siguió interesado en los temas que habíamos elaborado en el I.P.P.V., concretándose un trabajo de investigación en el que se recogían principalmente las ideas de Habraken y el S.A.R., basadas en la Teoría General de Sistemas. La subdivisión de la vivienda, su jerarquización y la flexibilidad definian al resultado final como un compromiso entre diversas alternativas. Con ello estábamos en el umbral de tener los instrumentos teóricos para poder racionalizar la vivienda y llegar, en su caso, a lo que considero puede ser la mejor aportación posible: la de los COMPONEN. TES COMPATIBLES.

Posteriormente se realizó el encargo de las viviendas de Móstoles, como experimentación de parte de las 


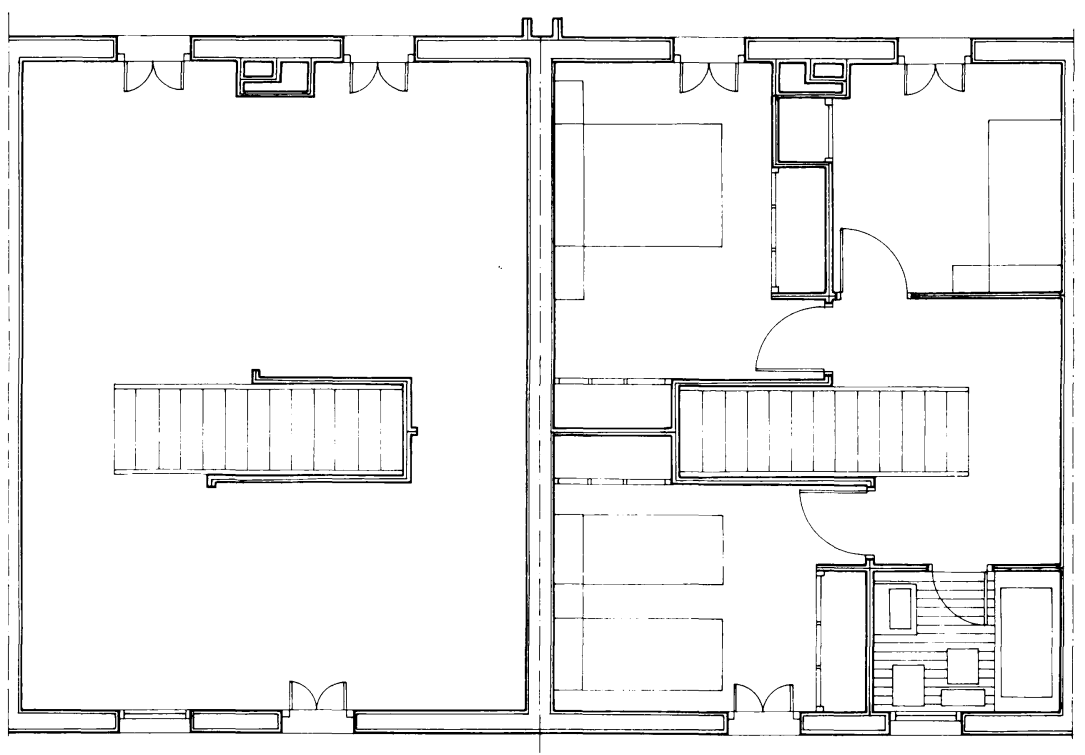

Planta alta

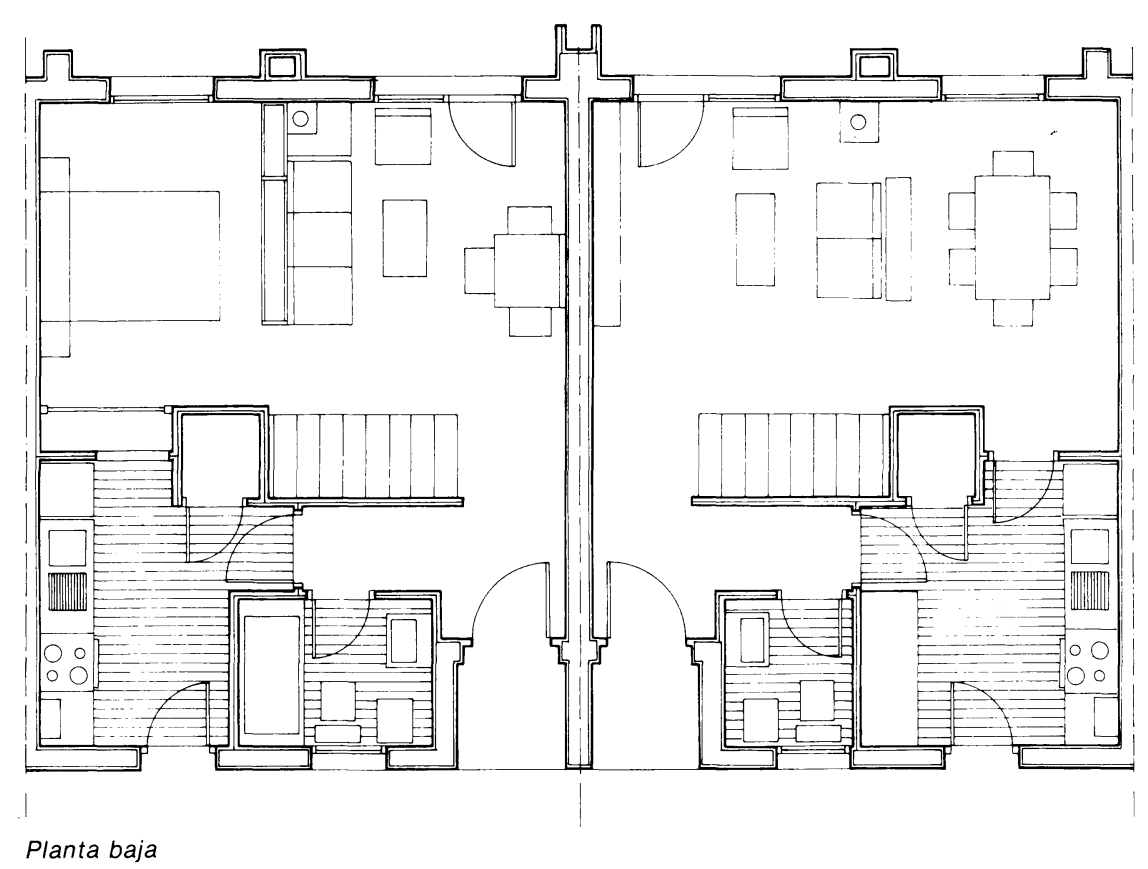

ideas anteriores. Este encargo se englobaba dentro de un programa general de viviendas experimentales y que comprendia tres proyectos pilotos: viviendas de bajo coste de adquisición, viviendas de bajo coste de mantenimiento y viviendas de bajo coste de los procesos construidos. Este proyecto se encuentra en el primer supuesto y se desarrolló de forma autónoma respecto a los demás, según un criterio establecido por la $\mathrm{Di}$ rección General de Arquitectura de la Consejería de la Ordenación del Territorio y Medio Ambiente de la Comunidad Autónoma de Madrid, con el fin de no incidir negativamente en los objetivos primordiales y especificos de cada programa.
Teniendo en cuenta que se trata de un programa pionero desde la Administración Pública, por no existir experiencias ejecutadas en este terreno, se llegó a tres conclusiones básicas:

1) Debe realizarse mediante soluciones constructivas en cierta medida tradicionales y universales, fácilmente asimilables para el futuro usuario.

2) El número de objetivos tiene que ser reducido dentro de la idea fundamental de hábitat abierto. 


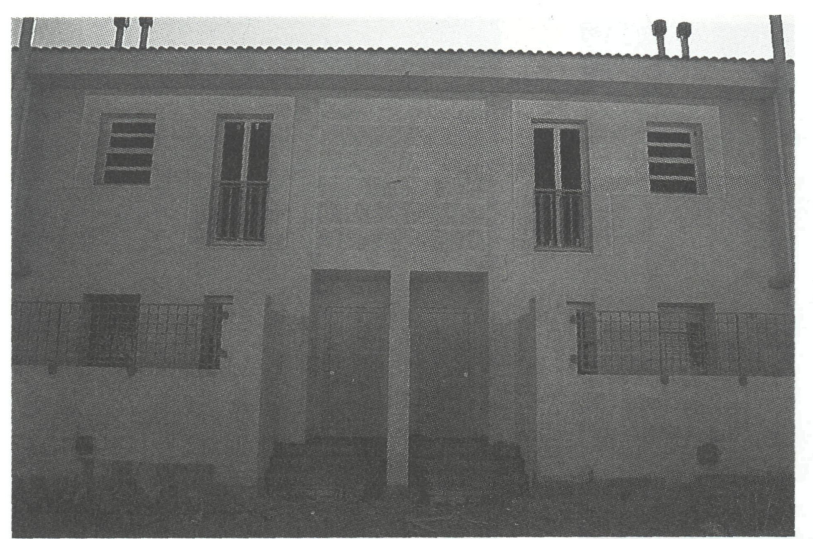

Entrada a viviendas. En el estado actual faltan los acabados en planta $1^{a}$ y en urbanización.

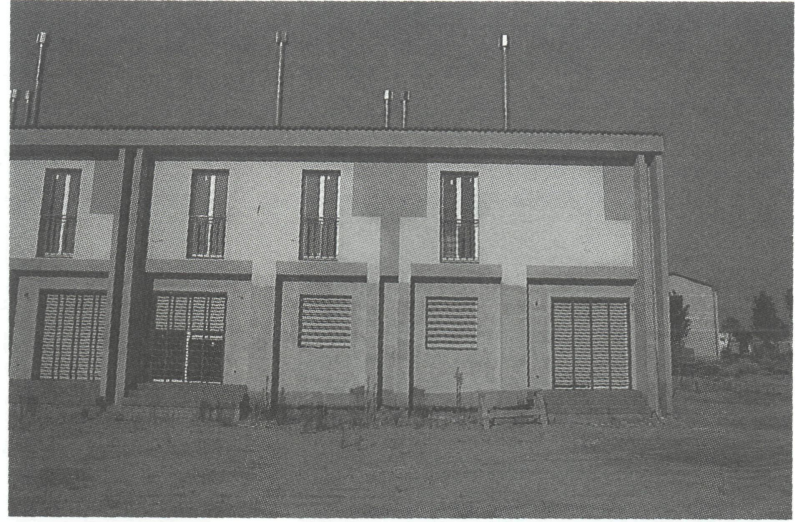

Alzado a patios posteriores.

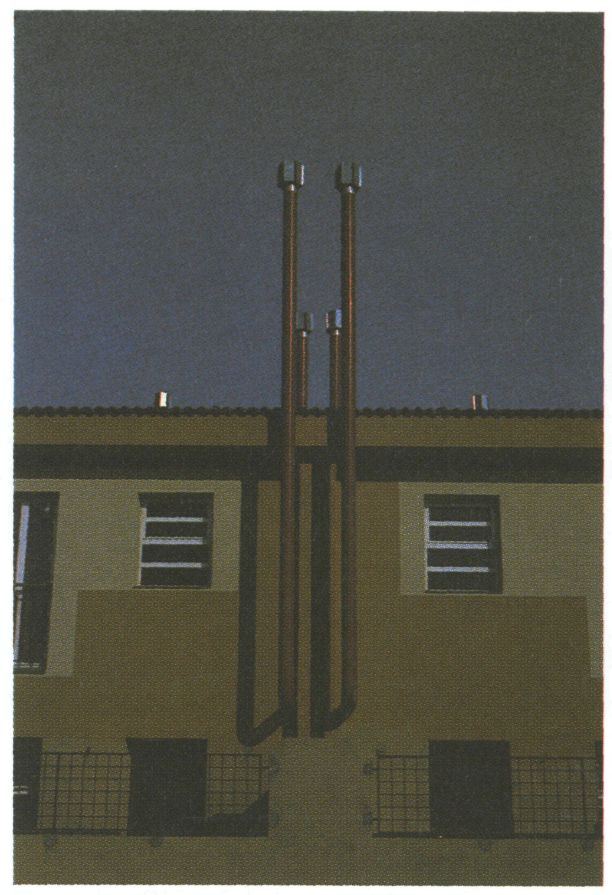

3) Esta experiencia debe tener un control para la posible verificación posterior de los resultados.

El proyecto tenía la intención de establecer una jerarquía de elementos desde el módulo básico, a semejanza del soporte de Habraken, que supone los cimientos y el saneamiento; la estructura; la envolvente y las acometidas. A este respecto me gustaría destacar que la teoría de los Soportes de Habraken es poco conocida porque, entre otras cosas, hay gente que la confunde con el soporte estructural o pilar cuando, por el contrario, es una de las teorías más racionales que se han llevado a cabo.
La jerarquia era, por tanto, la siguiente:

- Elementos Básicos.

- Elementos Primarios.

- Elementos Específicos.

- Elementos Secundarios.

- Elementos Aplazados.

\section{Elementos Básicos}

Son los que definen físicamente el módulo-soporte y se dan en todos los casos sin que influya el tipo de ter- 


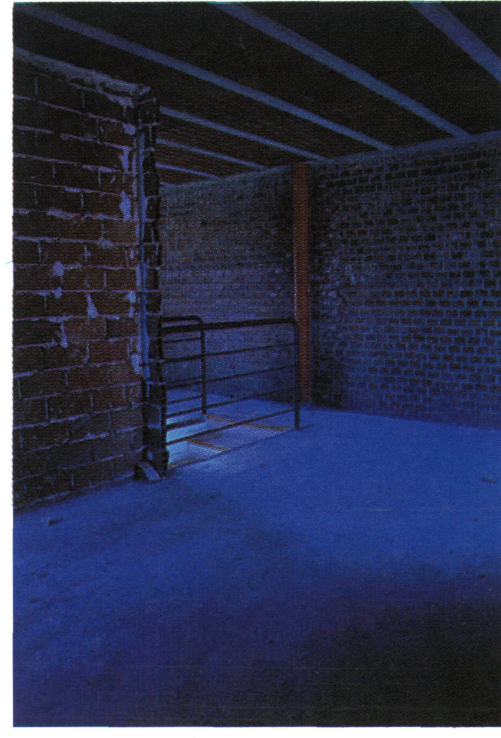

a

Interior planta alta

a) Antes de realizar ninguna actuación por parte del usuario.

b) Un caso después de una actuación.

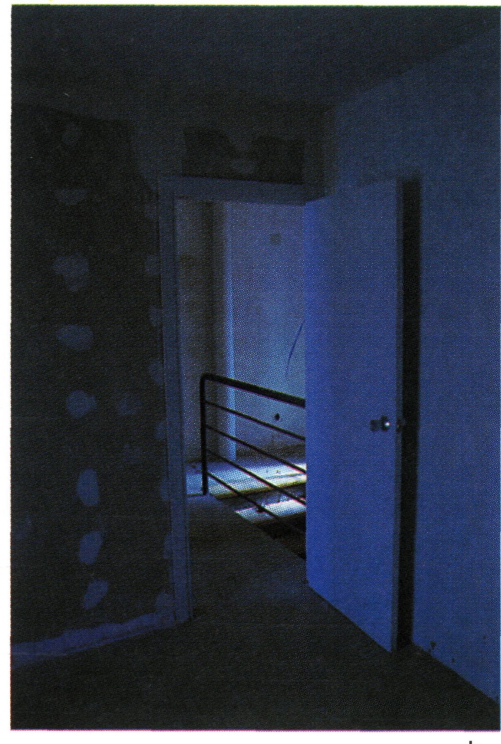

$b$

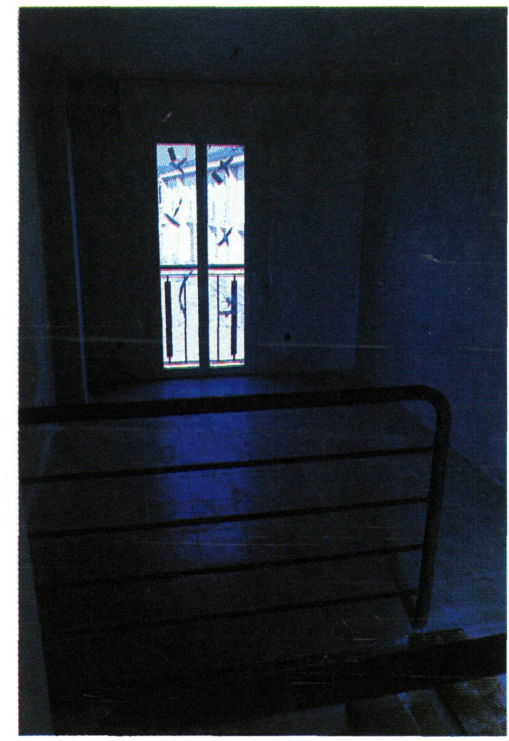

Desembarco de la escalera en planta alta cuando aún no se ha colocado una de las tabiquerias y la escalera se integra en una zona común.

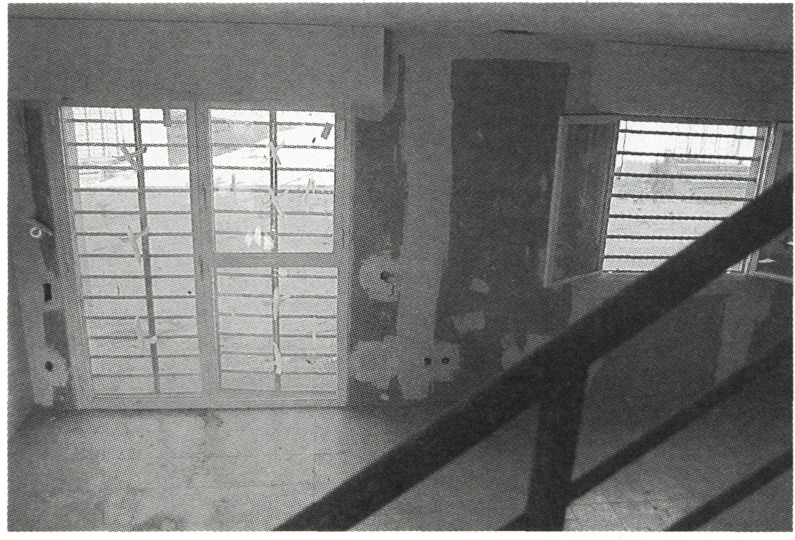

Vistas del salón desde la escalera.

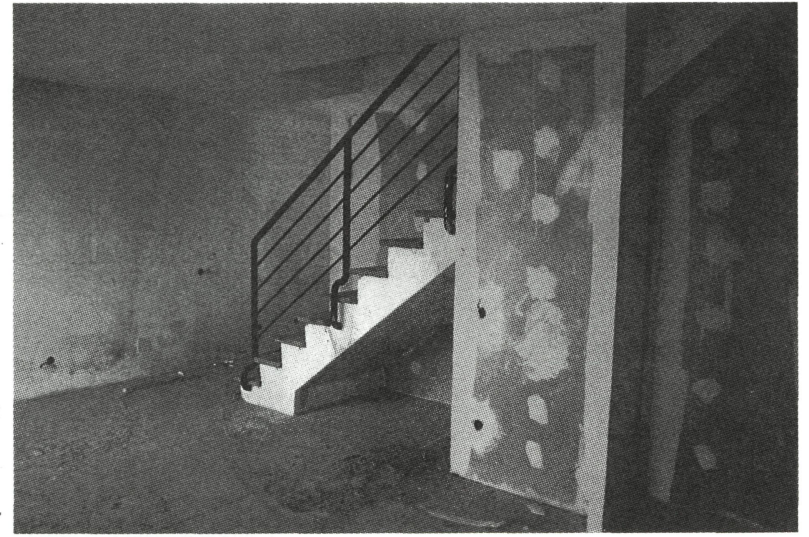

Escalera. Se aprecia cómo su espacio queda integrado en el salón.

- La comunicación vertical.

- La situación de los locales húmedos.

- El sistema de calefacción.

\section{Elementos Específicos}

Son los que hemos considerado como óptimos para el presente proyecto según las características del mismo. Se ha buscado como requisito que, siendo importantes en el desarrollo de la obra, puedan seguir teniendo utilidad posteriormente. Así, por ejemplo, a la necesidad de poner un aislamiento entre la planta acabada y la inacabada se ha buscado una solución mediante una lámina de Porexpan y una capa de mortero que además actúa posteriormente como suelo flotante. 


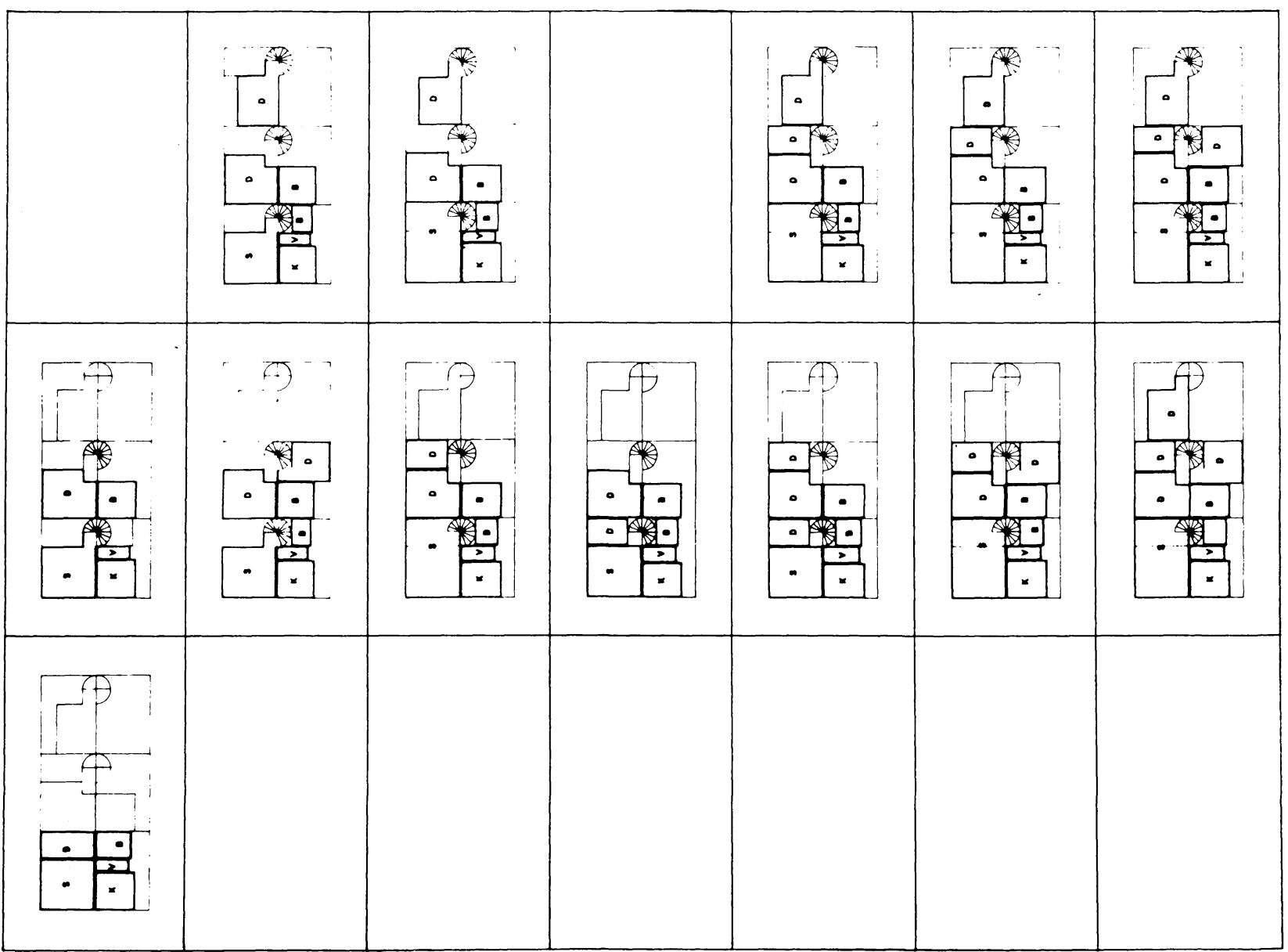

Estudio previo anterior al proyecto del esquema de desarrollo en planta; según las necesidades de dormitorios se traduce en la utilización' de una, dos o tres plantas según esquema.
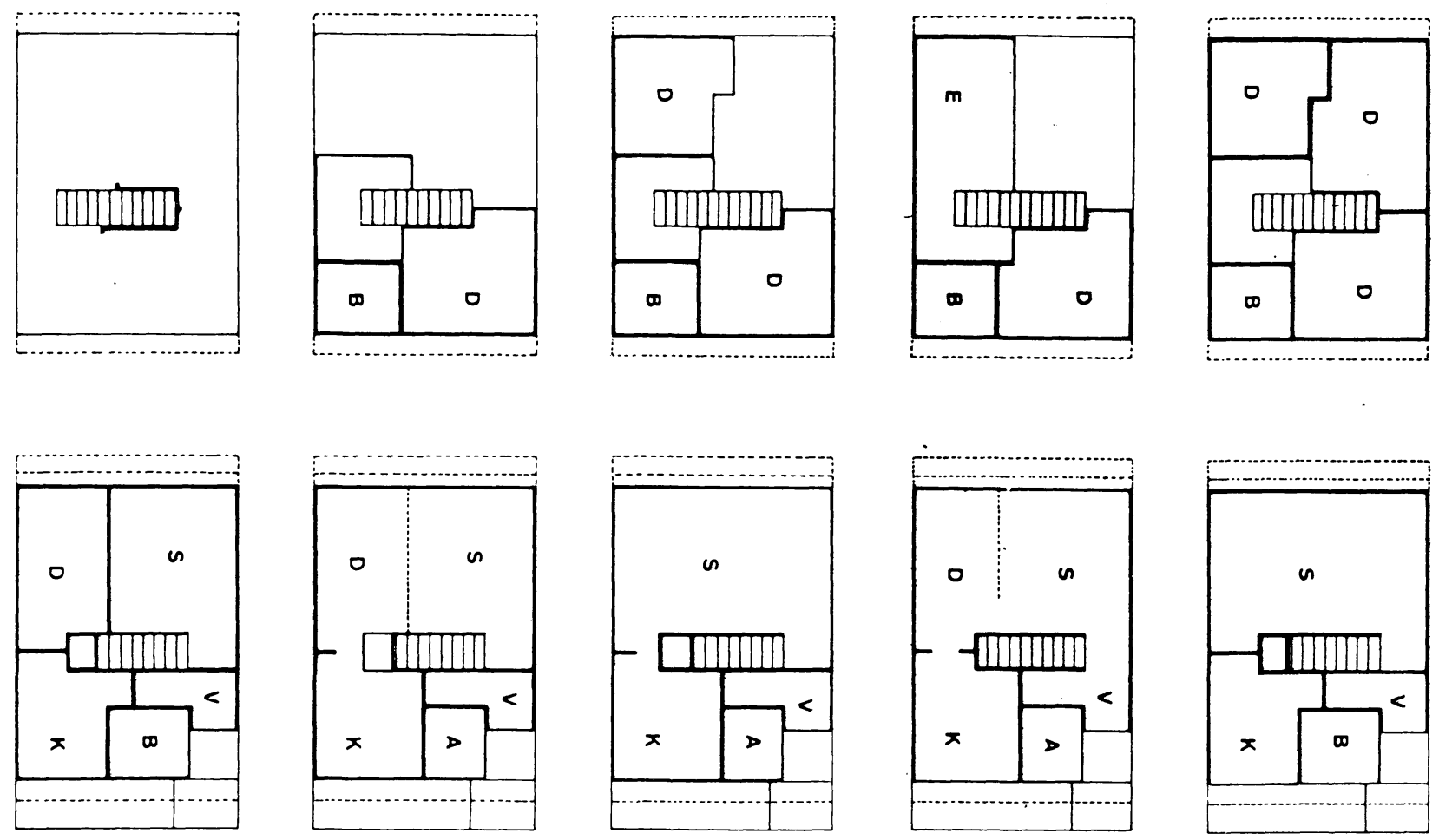

Esquema de las posibles alternativas de las plantas según las necesidades de los usuarios. Sin representar un orden cronológico, el lado izquierdo corresponde a la planta alta y el lado derecho corresponde a la planta baja. 

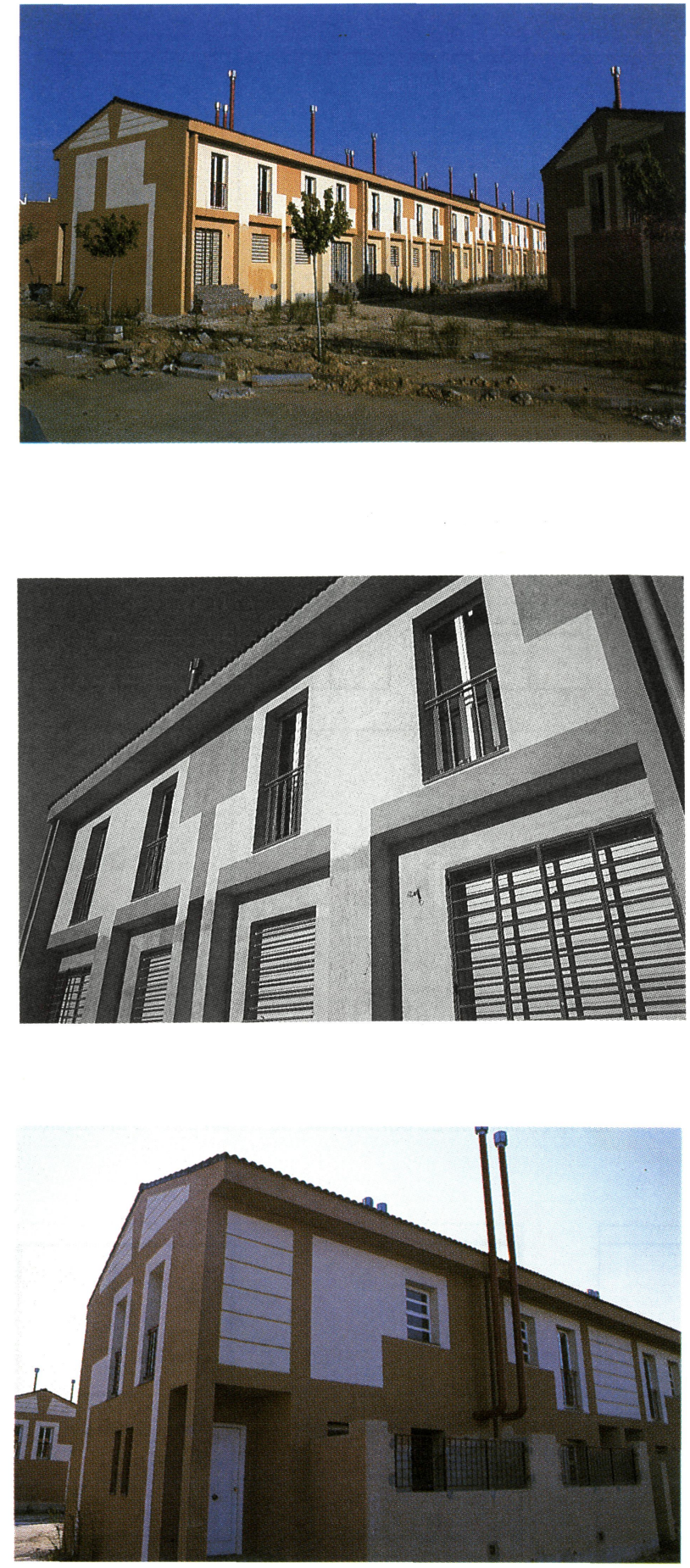

Son Elementos Específicos:

- El aislamiento exterior, evitando los puentes térmicos.

- El aislamiento en el forjado de planta $1 .^{a}$, que actúa como suelo flotante.

- El tabique provisional de separación entre cocina y aseo.

- El elemento separador del Estar, recuperable posteriormente como librería.

- El elemento provisional en planta baja, recuperable posteriormente para planta $1{ }^{\mathrm{a}}$

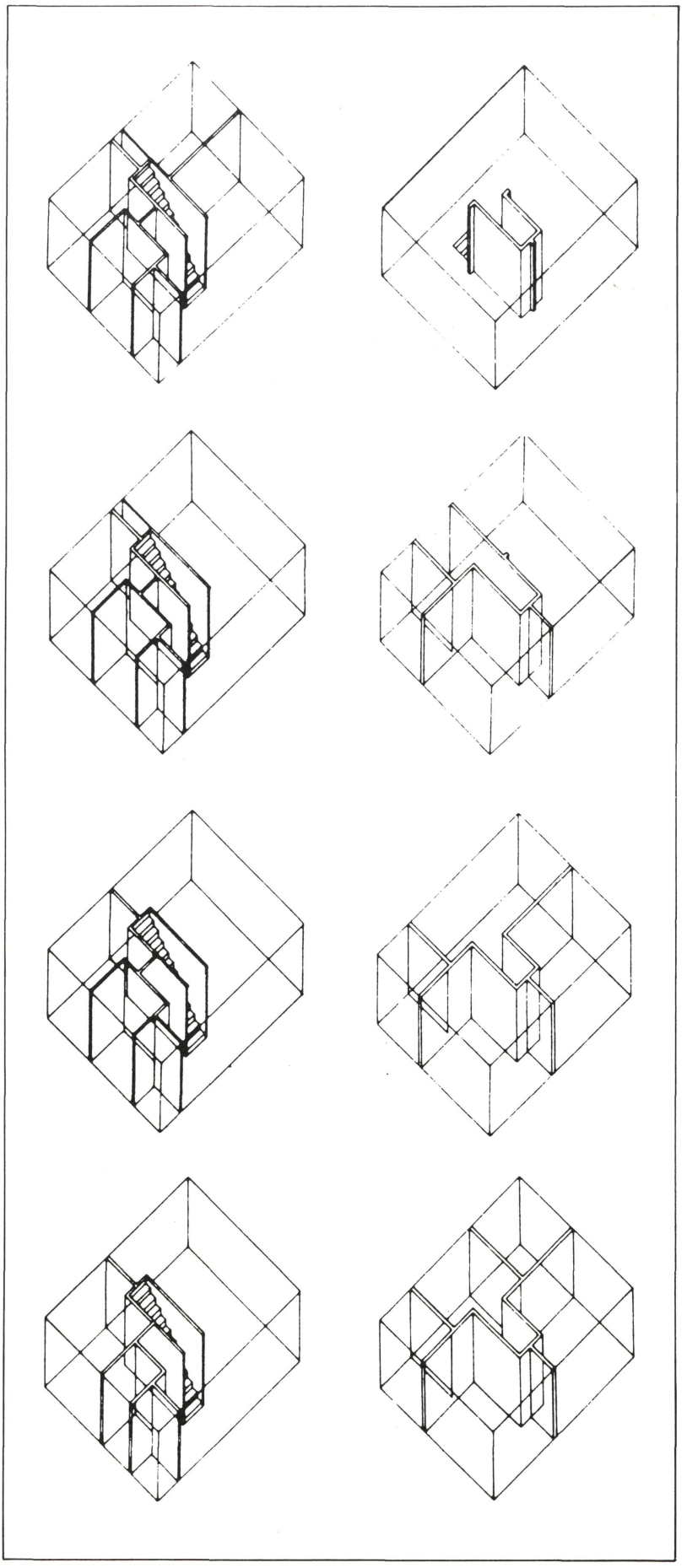

Esquema gráfico y volumétrico de un posible desarrollo en fases de planta baja y planta alta respectivamente.

- El elemento de cerramiento provisional de la escalera.

\section{Elementos Secundarios}

Son aquellos que en un programa de viviendas inacabadas podrían considerarse como no básicos, pero que por necesidad del proyecto se incluyen. En este apartado entrarían todos los acabados de planta baja como solados, pinturas, etc., así como los elementos del exterior de la vivienda. Es lo que marca, en definitiva, la diferencia entre planta baja con uso completo y $1 .{ }^{2}$ inacabada.

http://informesdelaconstruccion.revistas.csic.es 

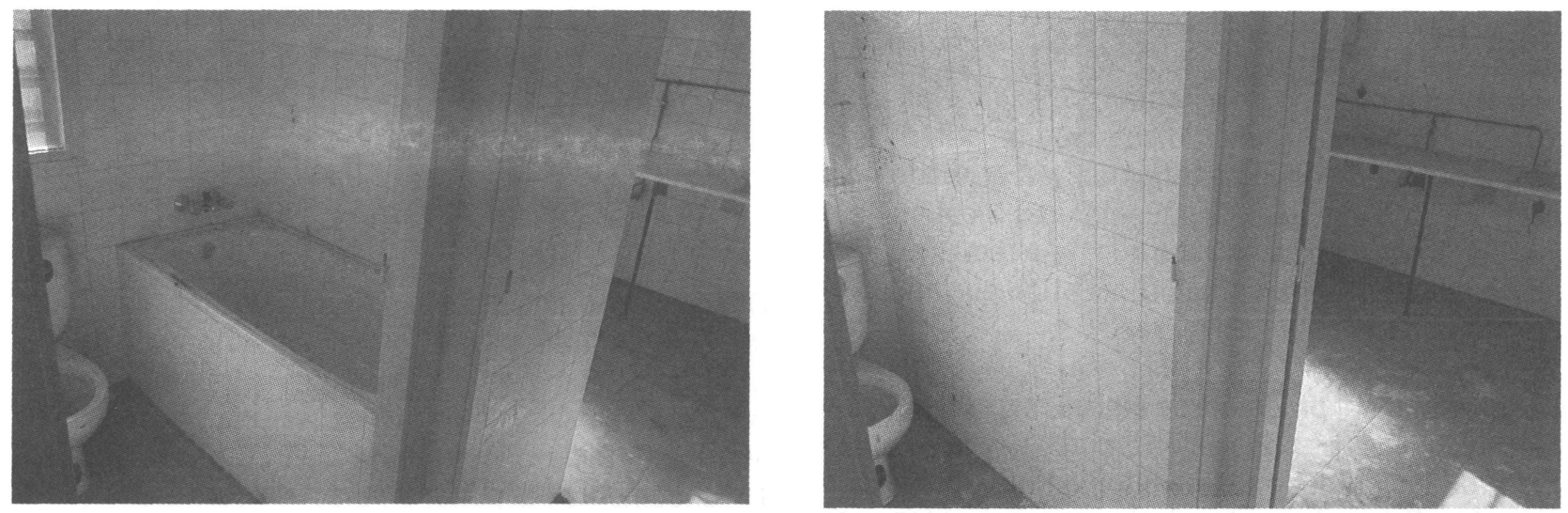

Interior planta baja con la alternativa: a) Aseo con baño. b) Aseo sin baño, cuyo espacio se integra en la cocina.
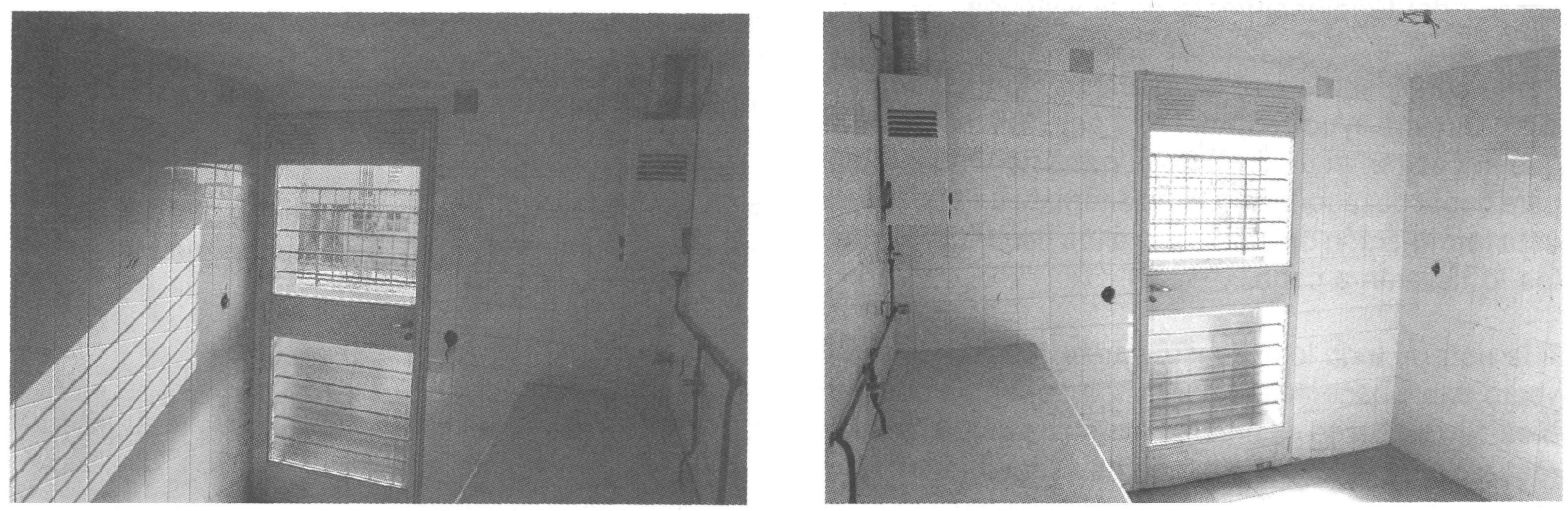

Interior planta baja vista desde la cocina con alternativa: a) Cocina junta a aseo con bañera. b) Cocina junto a aseo sin bañera.

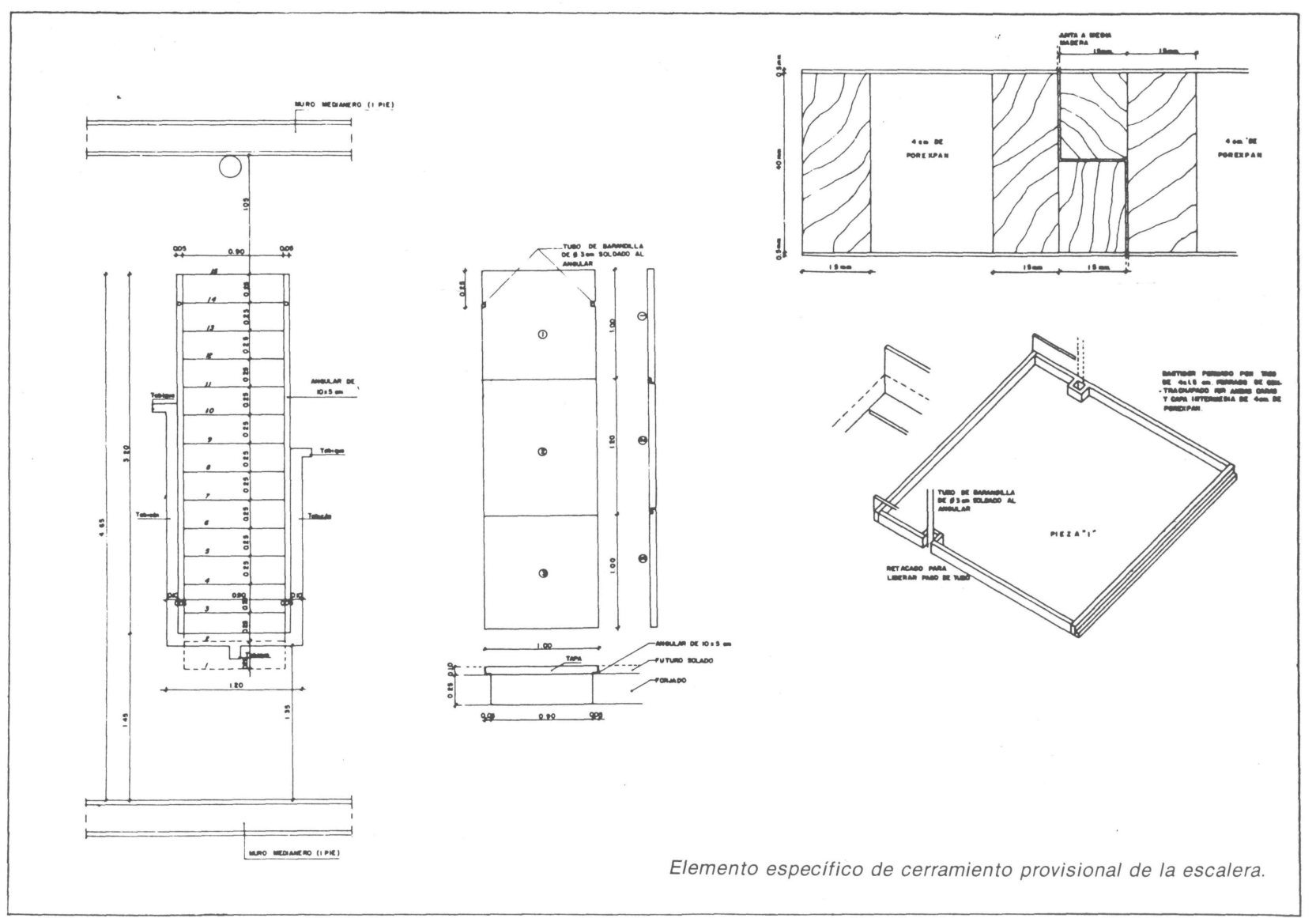




\section{Elementos Aplazados}

Son aquellos que no se ejecutan, dejando a los usuarios que lo hagan siguiendo sus propios criterios. Es el caso concreto de la distribución y el acabado de la planta $1{ }^{a}$ Sin embargo, la situación del local húmedo y la ubicación de huecos hace que las alternativas sean limitadas en un sentido lógico, cuestión que beneficia al proyecto.

El desarrollo del programa se realiza mediante el establecimiento de una separación cronológica que permite la introducción de los elementos anteriormente enumerados. Estos elementos darán respuesta a las sucesivas innovaciones, sin que por ello se deba perder el control del funcionamiento de la vivienda.

Se ha considerado que estos Elementos Específicos suponen una ayuda estimulante para los moradores y que necesitarian un nivel de información tecnológico para poder desarrollarse. Como alternativa se podría dar esta información de antemano a los usuarios, los cuales lo llevarán a cabo.

A la vista de todo lo expuesto parece lógico que el proyecto debía hacerse mediante componentes compatibles. Sin embargo es preciso tener en cuenta que para realizarlo de esta manera, que es más coherente con la idea general del proyecto, habría que haber podido contar con un proceso de producción de esos componentes, que, por desgracia, no contamos. De todas formas el proyecto, que tenía esa vocación y que se plasma físicamente así, podía tener una experiencia adecuada en cuanto a la idea de realizar la vivienda en el transcurso de un tiempo y con una participación activa del usuario. Incluso podía ser positivo establecer grados de aceptación mediante una construcción tradicional. De hecho hay que recordar el rechazo que produce todo lo que se asimile a los horribles prefabricados de los años sesenta. Tanto el volumen total como la propia subdivisión de las fachadas tiene el planteamiento coherente con la idea de los componentes com- patibles. La continuidad de fachadas, excepto las entradas, tiene un intento de flexibilidad interior.

\section{LA OBRA}

Desgraciadamente para el proyecto la Dirección General de Arquitectura de la Comunidad Autónoma de Madrid desapareció del Organigrama administrativo. El proyecto y su asignación presupuestaria pasaron al IVIMA (Instituto de la Vivienda de Madrid). El requerimiento fundamental, al poner en práctica esta experiencia piloto, era el seguimiento, para poder evaluar sus resultados. Otra condición fundamental era la agilidad administrativa, incluso en orden a dictar normativa excepcional que hiciera viable el experimento. EI IVIMA no es un organismo que tenga un tratamiento especifico para la investigación.

Por tanto, la continuidad y el rendimiento del experimento no están asegurados ni mucho menos.

\section{CONCLUSIÓN}

Podemos sacar en claro:

1) Que la investigación es necesaria y cara, sin resultados rápidos.

2) Que en España no hay un organismo especifico que lleve a cabo proyectos de investigación y los ponga en práctica, evaluando las conclusiones.

3) Que los arquitectos tienen que tomar conciencia de hacer planteamientos tecnológicos que permita a la industria realizar procesos de producción adecuados al tiempo en que vivimos, y no como viene siendo lo habitual, al revés. 